\title{
Treatments of post-surgical fistulas with particular emphasys to stem cells therapy
}

\author{
Francesco Petrella ${ }^{1}$ \\ Lorenzo Spaggiari ${ }^{1,2}$ \\ 1 Department of Thoracic Surgery, \\ European Institute of Oncology, Milan, Italy \\ 2 School of Medicine, University of Milan, Milan, Italy
}

Address for correspondence:

Francesco Petrella, MD

Department of Thoracic Surgery

European Institute of Oncology

Via Ripamonti 435, 20141 Milan, Italy

E-mail: francesco.petrella@ieo.it

\section{Summary}

Post resectional bronchopleural fistula is a pathological connection between the airway and the pleural space that may develop after surgical lung resection. It is still the most feared complication about after curative lung resection because current treatments are often far to be satisfactory. For this reason great attention has been reached about the healing effects promoted by stem cells through transformation into mature cells with a specialized function or by enhancing intrinsic repair mechanisms. This may represent an effective therapeutic option, as showed by our team, only partially explored to date.

Nevertheless, there is still a lack of consensus regarding the optimal management of a fistula, but an individualized approach is recommended. Several strategies have been suggested to manage this problematic condition with a variable success rate: invasive surgery, direct closure with re-enforcement of the pleura, or using flaps from pericardium, intercostal tissue or omentus. A less invasive option suggested by several Authors is the endoscopic use of fibrin glue or silver nitrate.

In conclusion, although cellular therapies are a new interesting therapeutic approach for the closure of airway fistulas, more basic research and clinical experiences are needed to get this promising therapy as a routine tool for treating this insidious post-surgical complication. Currently, a standard surgical and conservative approach still remain the first choice therapeutic option for postsurgical broncho-pleural fistulas.

KEY WORDS: bronchopleural fistula, mesenchimal stem cell, Eloesser flap, Clagget procedure.
Introduction

Post resectional bronchopleural fistula (BPF) is a pathological connection between the airways and the pleural space that may develop after lung resection (1). It may be caused by incomplete bronchial closure, impediment of bronchial stump wound healing, or stump destruction by residual neoplastic tissue. The incidence of BPF after thoracic surgery for lung cancer ranges from 1 to $4 \%$, whilst its mortality ranges from 12.5 to $71.2 \%$ (2).

BPF is still the most feared complication after curative lung resection (3); for this reason the healing effects promoted by stem cells - by transformation into mature cells with a specialized function or by enhancing intrinsic repair mechanisms may represent an effective and only partially explored therapeutic option $(4,5)$.

There is still a lack of consensus about the optimal management of the BPF, but individualized approach is usually recommended (6). Several strategies have
A post-surgical broncho-pleural fistula is more common in patients with inflammatory broncho-pulmonary diseases, particularly active tubercolosis. been employed to manage the problem with variable success: surgery, direct closure with re-enforcement of pleural, pericardial, intercostal or omental flaps may be necessary; as a less invasive option, fibrin glue has been used by several investigators (7).

Preoperative risk factors for the development of BPF are: fever, steroid use, elevated erythrocyte sedimentation rate and anemia; postoperative risk factors are: fever, steroid use, leukocytosis, tracheostomy and prolonged mechanical ventilation, repeated bronchoscopy for sputum suction and mucus plugging (8). Further risk factors meriting to be mentioned are an extensive mediastinal lymphadenectomy, ageing, and preoperative chemotherapy and radiotherapy.

BPF is more common after pneumonectomy than following lesser resection and it is more common after right-sided operation than left pneumonectomy; moreover, BPF occurring after pneumonectomy is clinically more devastating than after lobectomy or segmentectomy (9).

BPF is more common after resections for inflammatory disease of the lung, especially in patients with active tuberculosis and positive sputum.

\section{Clinical presentation}

A BPF can occur at any time during the postoperative 


\section{The clinical presen- tation of post-surgi- cal broncho-pulmo- nary fistula may be acute, subacute or chronic.}

tempt of reclosure.

period but more frequently occurs within 8 to 12 days after surgery; if seen within the first week after surgery, BPF may be due to a mechanical failure of closure of the stump and requires surgical exploration and an at-

The clinical presentation of a BPF may be acute, subacute, or chronic. The acute BPF is a life-threatening condition due to tension pneumothorax or asphyxiation from pulmonary flooding. The patient has dyspnea, subcutaneous emphysema, cough with expectoration of fluid or purulent material. There is mediastinal shifting on radiological images (6).

The subacute form is characterized by wasting malaise, fever and minimally productive cough; the presence of fibrosis in the pleural space is usually associated with this form preventing the mediastinal shift (6).

Chronic BPF presents with fever, productive cough and new or increasing air fluid levels on the chest $\mathrm{X}$-ray; in case of chronic tracheo-esophageal fistula, coughing and dyspnea are preferably observed during drinking and eating (6).

\section{Treatments}

\section{Chest tube}

Chest tube is always indicated in case of symptomatic

It is particulary useful in case of highflow BPF, to prevent hypertensive pneumothorax and mediastinal shifting as well as to drain empyema.

ron

is necessary to achieve closure of the fistula and to control the associate empyema. Initial drainage and subsequent direct closure of the bronchus by a manual suture technique and support of the suture line with an omental flap with eventual obliteration of the pleural space has been described for this purpose (13), but other Authors advocate - after stabilization of the patient - open drainage by establishing an Eloesser flap consisting in a U-shaped incision and the resection of a number of subjacent posterolateral ribs (Figure 3). This U-shaped flap is then folded into the pleural space creating a permanent communication after cleaning of the pleural space, then the bronchial stump is reclosed and reinforced with vascularized tissue. The subsequent sterilization of the pleural space is accomplished by the Clagget maneuver, consisting in continuous drainage and irrigation of the cavity with antibiotic solution (14).

In the setting of a coexisting BPF, a direct Clagget procedure - without previous closure of the fistula - cannot be performed to avoid solution inhalation, and it is therefore recommended in case of pleural empyema without active BPF.

Trans-sternal trans-pericardial exposure and division of a long bronchial stump associated with a bronchopleural fistula has also been suggested as a possible solution, as firstly described by Abruzzini in 1961 (15).

Although either right thoracotomy approach to close left bronchial stump fistulae as well as carinal resection to eradicate a fistula in patients with a short bronchial stump have been described $(12,16)$, their clinical application remains anecdotal.

BPF rarely occurs after lobectomy, but in this case the management of the open bronchial stump and the frequently related empyema is similar to that following a pneumonectomy except for the presence of residual pulmonary tissue in the same emithorax that may modify the clinical management to a variable extent (9). Occasionally, the management of a post-lobectomy BPF leads to the indication of a complete surgical pneumonectomy, but the reported complication rate usually exceeds $50 \%$ (17). so its long-term use is contraindicated (10).

The chest tube should be of sufficient diameter to allow adequate drainage of the air leak; a larger diameter is therefore necessary in case of high-flow BPF (11).

\section{Surgery}

Early in the postoperative period - up to 7 or even 14 days - reoperation and repair of the bronchial stump may be indicated; with operative repair, coverage of the

In most situations when a major BPF is present, more aggressive measures to achieve closure of the fistula and to control the associate empyema are necessary. new bronchial suture line is mandatory: a transposed muscle flap, the pericardial fat pad or an omental pedicle flap may be used (12). In most situations when a major BPF is present, a more aggressive approach

\section{Bronchoscopic techniques}

Initially used only for evaluation of the stump and for the exclusion of tuberculosis, flexible bronchoscopy has been gaining acceptance as a diagnostic and therapeutic modality in patients with BPF (6).

Multiple sealing compounds have been used by direct application to the fistula through the rigid or flexible bronchoscope; this technique offers a minimally invasive alternative to poor candidates for surgery who are unable to tolerate a ma-

We first described the
successful closure of
a BPF following right
extrapleural pneumo-
nectomy by autolo-
gous bone marrow
derived mesenchymal
stem cell bronchosco-
pic transplantation,
without using sealing
agents.




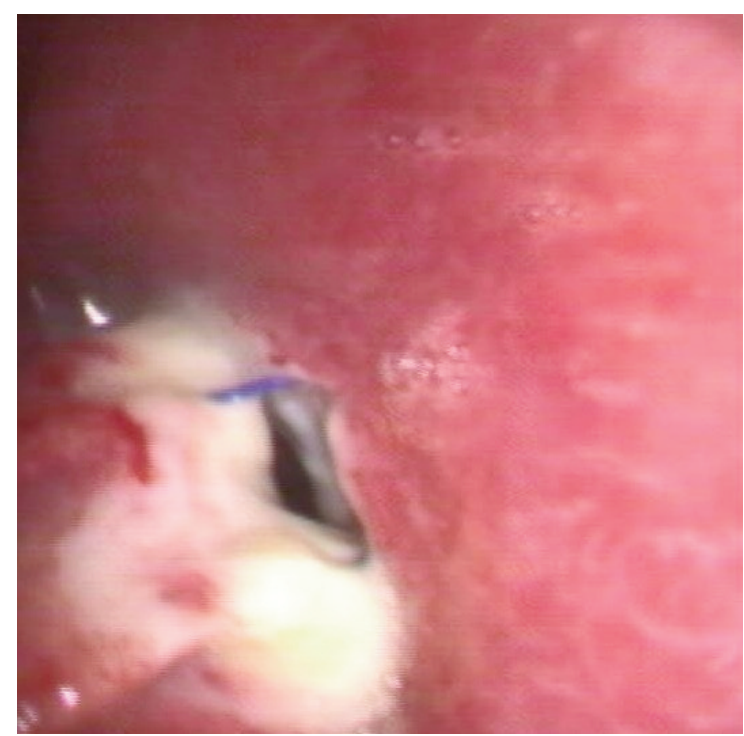

Figure 1 - Endoscopic view of a right main stump bronchus fistula.

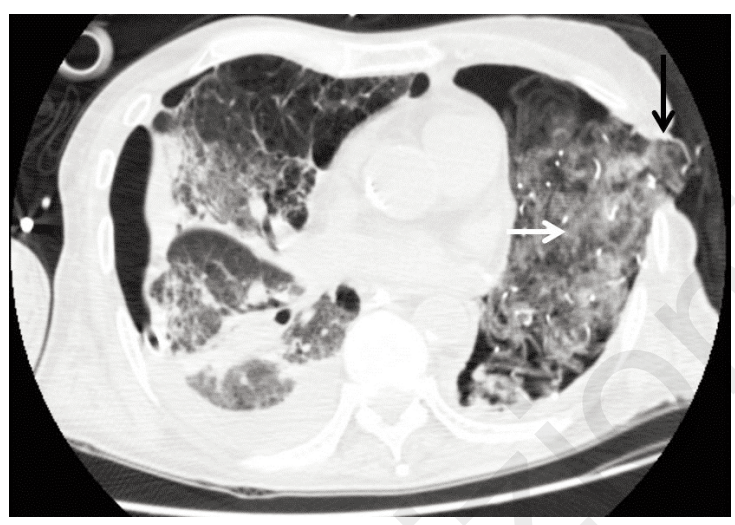

Figure 3 - CT scan of a left-sided Eloesser procedure; note the left pleural cavity filled in with gauze (white arrow) and the thoracostomy (black arrow).

jor thoracic procedure.

The bronchoscopic management includes the most interesting and apparently successful techniques; however, all the reported experiences are limited to case series or to uncontrolled studies recruiting few patients without enough information to determine which is the most effective technique (6).

Fibrin glue: the placement of fibrin sealant through the flexible fiberoptic bronchoscope was first described by Hartmann and Rausch in 1977 (18); by this procedure a fibrin clot forms over the fistula, sealing the leak. It is supposed that the fibrin glue is eventually reabsorbed, preventing foreign body reaction.

Ethanol: the use of absolute ethanol by direct injection into the submucosal layer of a fistula has been described with good results for patients with a postoperative central BPF with an orifice smaller than $3 \mathrm{~mm}$ in diameter (19).

Cyanoacrylate Glue: this glue initially seals by acting as a plug and later by inducing an inflammatory re-

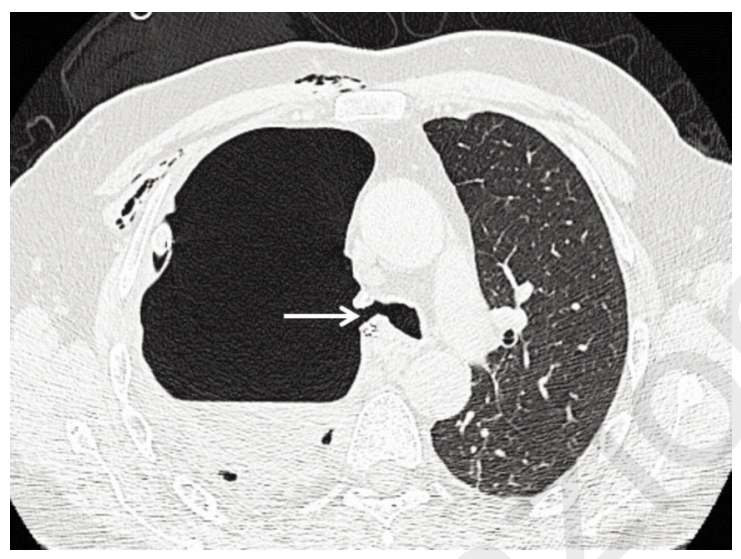

Figure 3 - CT scan of a right main stump bronchus fistula (white arrow) following right pneumonectomy.

sponse leading to local fibrosis and mucosal proliferation, permanently sealing the defect (6); the cyanoacrylate glues polymerize into solid material on contact with body fluids or tissue (20).

Albumin-glutharaldehyde tissue adhesive: it has been proposed to seal air leaks from pulmonary parenchyma and BPF. It has been proven to be effective in sealing lung lacerations and in preventing air leakage from suture or staple lines of emphysematous lungs. It was also successful in sealing BPF when applied either intra-bronchially through the rigid bronchoscope or during thoracotomy (21).

Gel Foam: it has been used by flexible or rigid bronchoscope; it presents the advantage of being almost totally re-adsorbed after being moistened with normal saline solution (22).

Silver nitrate: it has been injected through the flexible or rigid bronchoscope to seal stump leaks by the sclerotizing action of the silver nitrate, generating fibrosis and occluding scar and granulation tissue (23).

Stents: the goal of the stent is providing as tight seal in the airway as possible to prevent aspiration and pneumonitis (6). Airways stents have been extensively used mostly for the management of esophageal-toairways fistulas (24).

Stem Cells: in 2008 Garcia-Olmo et al. first described a successful closure of a tracheo-mediastinal fistula resulting from laser treatment of tracheal cancer by bronchoscopic injection of autologous adipose-derived mesenchymal stem cells suspended in fibrin glue (25).

In 2015 we first described the successful closure of a BPF following right extrapleural pneumonectomy by autologous bone marrow derived mesenchymal stem cell bronchoscopic transplantation, without using fibrin glue or other sealing agents (26) after a previous experimental study on a large animal model, in which post resectional BPF was successfully sealed by autologous bone-marrow derived mesenchymal stem cell suspended in fibrin glue (27). We plan to continue either on basic research and clinical experience with this promising technique. 


\section{Conclusion}

From the beginning of modern thoracic surgery, many complex procedures have been advocated as salvage therapy for bronchopleural fistula: muscle flap closure, completion lobectomy or pneumonectomy, and thoracoplasty are only some examples of the surgical options; open window thoracostomy - consisting of rib resection and daily medications by gauzes - is one of the most effective rescue treatments, but on the other hand, it is one of the most aggressive and psycologically disabling operations a patient can undergo (28). With the advent of flexible bronchoscopy, a plethora of endoscopic treatments have been proposed for bronchopleural fistula closure, fib-

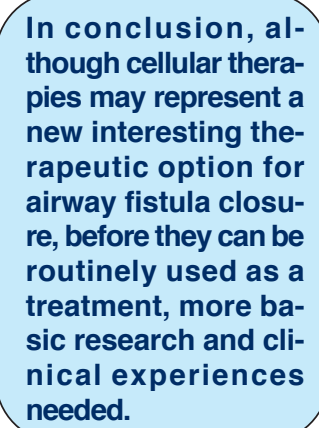
caliber fistula can be managed by a pure bronchoscopic approach, given that the failure rate may be not negligible.

In conclusion, although cellular therapies may represent a new interesting therapeutic option for airway fistula closure, more basic research and clinical experiences are needed before they can be routinely used. So, a standard surgical and conservative approaches still remain the most currently used therapeutic option.

\section{Acknowledgments}

The Authors thank Ms Federica Castoldi for her valuable support.

\section{References}

1. Petrella F, Toffalorio F, Brizzola S, De Pas TM, Rizzo $\mathrm{S}$, Barberis M, Pelicci P, Spaggiari L, Acocella F. Stem cell transplantation effectively occludes bronchopleural fistula in an animal model. Ann Thorac Surg. 2014 Feb;97(2):480-3.

2. Sonobe M, Nakagawa M, Ichinose M, Ikegami N, Nagasawa M, Shindo T. Analysis of risk factors in bronchopleural fistula after pulmonary resection for primary lung cancer. Eur J Cardiothorac Surg. 2000;18: 519-23.

3. Gomez-de-Antonio D, Zurita M, Santos M, Salas I, Vaquero J, Varela A. Stem cells and bronchial stump healing. J Thorac Cardiovasc Surg. 2010;140:1397401.

4. Wu Y, Chen L, Scott PG, Tredget EE. Mesenchymal stem cells enhance wound healing through differentiation and angiogenesis. Stem Cells.
2007;25:2648-59.

5. Mellough CB, Sernagor E, Moreno-Gimeno I, Steel $\mathrm{DH}$, Lako M. Efficient stage-specific differentiation of human pluripotent stem cells toward retinal photoreceptor cells. Stem Cells. 2012;30:673-86.

6. Lois M, Noppen M. Bronchopleural fistulas: An overview of the problem with special focus on endoscopic management. Chest. 2005;128:3955-65.

7. Shrestha $P$, Safdar SA, Jawad SA, Shaaban $H$, Dieguez J, Elberaqdar E, Rai S, Adelman M. Successful closure of a bronchopleural fistula by intrapleural administration of fibrin sealant: a case report with review of literature. N Am J Med Sci. 2014 Sep;6(9):487-90. doi: 10.4103/1947-2714.141660.

8. Sato M, Saito Y, Fujimura S, Usuda K, Takahashi S, Kanma K, Imai S, Suda H, Nakada T, Hashimoto K. Study of postoperative bronchopleural fistulas: analysis of factors related to bronchopleural fistulas. Nippon kyobu Geka Gekkai Zasshi. 1989;37:498-503.

9. Ponn RB. Complications of pulmonary resection in: General Thoracic Surgery, Sixth Edition, Volume 1, Chapter 37, pp. 554-586. Lippincott Williams \& Wilkins.

10. Miller Ks, Sahn SA. Chest tubes: indications, technique, management and complications. Chest. 1987; 91:258-264.

11. Swenson EW, Birath G, Ahbeck A. Resistance to airflow in bronchospirometric catheters. J Thorac Surg. 1957;33:275-281.

12. Brutel de la Riviere A, Defauw JJ, Knaepen PJ, van Swieten HA, Vanderschueren RC, van den Bosch JM. Transsternal closure of bronchopleural fistula after pneumonectomy. Ann Thorac Surg. 1997;64: 954.

13. Puskas JD, Mathisen DJ, Grillo HC, Wain JC, Wright $\mathrm{CD}$, Moncure AC. Treatment strategies for bronchoplerual fistula. J Thorac Cardiovasc Surg. 1995; 109:989.

14. Pairolero PC, Arnold PG, Trastek VF, Meland NB, Kay PP. Postpneumonectomy empyema: the role of intrathoracic muscle transposition. J Thorac Cardiovasc Surg. 1990;99:958.

15. Abruzzini P. Trattamento chirurgico delle fistole del bronco principale consecutive a pneumonectomai per tubercolosi. Chir Torac. 1961;14:165.

16. Perelman MI. Late treatment of chronic bronchopleural fistula with long stump after pneumonectomy. In Eschapasse H, Grillo H (eds): International Trends in General Thoracic Surgery, Vol 2, Philadelphia: WB Saunders, 1987.

17. McGovern EM. Completion pneumonectomy: indications, complications and results. Ann Thorac Surg. 1988;46:141.

18. Hartmann W, Rausch V. A new therapeutic application of the fiberoptic scope [letter]. Chest. 1977:71: 237.

19. Takaoka K, Inoue S, Ohira S. Central bronchopleural fistulas closed by bronchoscopic injection of absolute ethanol. Chest. 2002;122:374-378.

20. Menard JW, Prejean CA, Tucker WY. Endoscopic closure of bronchoplerual fistulas using a tissue adhesive. Am J Surg. 1988;155:415-416. 
21. Potaris K, Mihos P, Gakidis I. Preliminary results with the use of an albumin-glutharaldehyde tissue adhesive in lung surgery. Med Sci Monit. 2003;9:P179P183.

22. Jones DP, David I. Gelfoam occlusion of peripheral bronchoplerual fistulas. Ann Thorac Surg. 1986;42: 334-335.

23. Høier-Madsen K, Schulze S, Møller Pedersen V, Halkier E. Management of bronchopleural fistula following pneumonectomy. Scand J Thorac Cardiovasc Surg. 1984;18(3):263-6.

24. Colt HG, Meric B, Dumon JF. Double stents for carcinoma of the esophagus invading the tracheobronchial tree. Gastrointest Endosc. 1992;38:485489.
25. Alvarez PD, García-Arranz M, Georgiev-Hristov T, García-Olmo D. A new bronchoscopic treatment of tracheomediastinal fistula using autologous adiposederived stem cells. Thorax. 2008 Apr;63(4):374-6.

26. Petrella F, Spaggiari L, Acocella F, Barberis M, BelIomi M, Brizzola S, Donghi S, Giardina G, Giordano R, Guarize J, Lazzari L, Montemurro T, Pastano R, Rizzo S, Toffalorio F, Tosoni A, Zanotti M. Airway fistula closure after stem-cell infusion. $\mathrm{N}$ Engl J Med. 2015 Jan 1;372(1):96-7.

27. Petrella F, Toffalorio F, Brizzola S, De Pas TM, Rizzo S, Barberis M, Pelicci P, Spaggiari L, Acocella F. Stem cell transplantation effectively occludes bronchopleural fistula in an animal model. Ann Thorac Surg. 2014 Feb;97(2):480-3. 